\title{
PROTECTIVE EFFECTS OF CELOSIA ARGENTEA LINN, VITAMIN E AND DEXAMETHASONE ON RADIATION-INDUCED DAMAGE ON THE DEVELOPING RAT CEREBELLUM.
}

\author{
${ }^{1} \mathrm{KANU}$, LOVE CHIOMA, ${ }^{1}$ OWOEYE, OLATUNDE, ${ }^{1}$ IMOSEMI, INNOCENT OHIORENUAN, *1,2MALOMO, \\ ADEFOLARIN OBANISHOLA \\ Affiliation: Departments of Anatomy ${ }^{1}$ and Surgery ${ }^{2}$, College of Medicine, University of Ibadan, Ibadan, \\ Nigeria.
}

Correspondence to Prof. A.O. Malomo, Departments of Anatomy and Surgery, College of Medicine, University of Ibadan, Ibadan, Nigeria. Phone: +2348034852526. E-mail: ademalomo@yahoo.com.

\section{ABSTRACT}

The potential neuroprotective effect of aqueous extract of Celosia argentea Linn (AECA), Vitamin E (Vit E) and Dexamethasone (Dexa) on radiation-induced damage on the developing rat cerebellum was studied. Forty-two female rats weighing between $147 \mathrm{~g}$ and $222 \mathrm{~g}$ were randomized into six groups $(\mathrm{N}=7)$. Control group - Group I, Irrad group - Group II, AECA group - Group III, AECA + Irrad group Group IV, Vit E + Irrad group - Group V and Dexa+ Irrad group - Group VI. Rats were mated and pregnant rats were exposed to $2.5 \mathrm{~Gy}$ gamma radiation on gestation day 7 . The administration of 400 $\mathrm{mg} / \mathrm{kg}$ of AECA, $500 \mathrm{mg} / \mathrm{kg}$ of Vit $\mathrm{E}$ and $0.005 \mathrm{ml} / \mathrm{rat}$ of Dexa started from gestation day 1 till postnatal day 28. Postpartum, 5 pups from each group were exposed to behavioural and biochemical tests and then sacrificed. Brain tissue fixed in $10 \%$ formalin, processed by paraffin wax method was stained with $\mathrm{H} \& \mathrm{E}$ and Cresyl violet stains for histology. Radiation significantly $(\mathrm{p}<0.05)$ reduced gross, behavioural, histological and histomorphometric parameters, while eliciting oxidative stress relative to control group on post-natal days 7, 14, 21 and 28. Treatment with AECA, Vit E and Dexa with radiation significantly $(p<0.05)$ reduced most of the alterations induced by radiation in the various parameters. This study confirmed development of oxidative stress in rat pups using single dose $2.5 \mathrm{~Gy}$ gamma-irradiation. The antioxidant properties of AECA and Vit $\mathrm{E}$ and the anti-inflammatory property of Dexa were able to mitigate the alterations in the developing rat brain parameters.

Key words: Gamma-radiation, neuroprotective, plant products, rat brain.

\section{INTRODUCTION}

Radiotherapy has played important role in the treatment of cancers of various types, but it may cause tissue injury to nearby normal tissue (Malomo et al., 2005). Since the destruction of cancer cells is as important as the protection of normal tissue adjacent to the cancerous tissue, there is a continuous search for radio-protective substances that would mitigate side effects during radio therapeutic procedures (Owoeye and Malomo, 2015). It has been reported that prenatal exposure to ionizing radiation can interfere with embryonic and fetal development, depending on dose and gestational age in which exposure occurs (De Santis et al., 2007). It has been reported that radiation toxicity is mediated by oxidative damage via the mechanism of free radical injury of adjacent tissues which could damage biologically active molecules and possible cell death (Adaramoye et al., 2010; Owoeye et al. (2011)). Substances possessing antioxidant capabilities could mitigate radiation injury as previously reported (Sarkar et al., 2014; Owoeye and Elumelu, 2015). Plant products being either non-toxic or less toxic have been found to offer an alternative to synthetic compounds in preventing radiation injury as in the case of Vernonia amygdalina (Owoeye et al., 2011), Launaea taraxacifolia (Owoeye and Malomo, 2015), and tomato pomace (Owoeye and Elumelu, 2015) among others. Other 
substances known to contain antioxidants include Celosia argentea L. and vitamin E and dexamethasone, known for its anti-inflammatory and membrane stabilizing property were then studied against radiation toxicity in the cerebellum of rats.

Celosia argentea $L$. is an herbaceous plant which belongs to the family - Amarathacaceae and is one of the leading leaf vegetables in southwestern Nigeria, where it is known as 'soko yòkòtò' in Yoruba language, meaning 'make husbands fat and happy' (Grubben and Denton, 2004). Malomo et al. (2011) and Verma and Demla (2012) reported that Celosia argentea $L$. is rich in flavonoids, saponins and polyphenols possessing strong antioxidant properties among other important bioactive substances. We hypothesized that these bioactive substances via their antioxidant activity should protect irradiated tissue from the effect of oxidative damage.

Vitamin E (a-Tocopherol), a fat-soluble vitamin is the primary membrane bound, chain-breaking antioxidant that has been reported to protect against lipid peroxidation-induced tissue damage (Bharrhan et al., 2010). Vitamins are ideal antioxidants to increase tissue protection from oxidative stress due to their easy, effective and safe dietary administration in a large range of concentrations. Vitamin $\mathrm{E}$ has been shown to decrease radiation-induced chromosome damage in human tumor cells but not in normal cells and has an inhibitory effect on a variety of cancer cells (Borek, 2004). Sezen et al. (2008) reported the radioprotective role of vitamin $E$ in brain and retinal damage. Dexamethasone is a synthetic corticosteroid which affects the function of many cells within the body and suppresses the immune system. Corticosteroids also blocks inflammation and are used in a wide variety of inflammatory diseases affecting many organs (Ogbru, 2012). Dexamethasone is a corticosteroid with marked anti-inflammatory and anti-allergic properties and as a catabolic steroid, it breaks down stored fat, sugar and protein necessary in times of stress (Brooks, 2001).

The present study was therefore designed to investigate the potential protective capacity of natural occurring antioxidants in Celosia argentea $L$. on the damaging effect of radiation on developing rat cerebellum using Vitamin $E$ as a standard antioxidant and dexamethasone as an anti-inflammatory reference. It was anticipated that information obtained from the study could further research aimed at reducing radiation side effects.

\section{MATERIALS AND METHODS}

The plant material Celosia argentea Linn was purchased from Bodija market, Ibadan, Oyo State, Nigeria in May, 2013 and was authenticated at the Forest Research Institute of Nigeria (FRIN) Ibadan, Nigeria where a voucher specimen (FHI. 109675) was deposited at the herbarium. Phytochemical analysis was conducted on the leaves of Celosia argentea Linn in the Department of Pharmacognosy, University of Ibadan, Nigeria, to determine the bioactive compounds. Fresh leaves of plant after authentication were prepared using the method of Malomo et al. (2011). Briefly: the leaves were oven-dried at $40^{\circ} \mathrm{C}$ at a constant weight and the dried leaves pulverized. A portion of the powder $(400 \mathrm{~g})$ was extracted in $4000 \mathrm{~mL}$ of distilled water and left at room temperature for 48 hours before been filtered. The filtrate was concentrated over a water bath to give a total yield of $55.24 \mathrm{~g}$ and a percentage yield of $13.8 \%$. Forty-two (42) female rats of Wistar strain weighing between $147 \mathrm{~g}$ and $222 \mathrm{~g}$ were purchased from the Animal House, College of Medicine University of Ibadan. The animals were acclimatized for two weeks and then randomized into six groups of seven animals each. They were kept in plastic cages having dimension of $39 \times$ $29 \times 27 \mathrm{~cm}$ and soft wood shavings employed as bedding in the cages and fed with standard rat feed (mice cubes) from Ladokun Feeds, Ibadan, Nigeria and water provided ad libitum. They were housed in the College of Medicine Central Animal House in a light/dark cycle. The experimental protocols were carried out to 
conform to the acceptable guidelines on the ethical and humane use of animals in research (Public Health Service, 1996).

Group I: received distilled water only and served as control.

Group II: received 2.5 Gy of gamma rays only on day 7 of gestation.

Group III: received $400 \mathrm{mg} / \mathrm{kg}$ of AECA only (from day 1 gestation till day 21 postpartum).

Group IV: received 2.5 Gy of gamma rays on day 7 of gestation $+400 \mathrm{mg} / \mathrm{kg}$ of AECA (from day 1 gestation till day 21 postpartum).

Group V: received 2.5 Gy of gamma rays on day 7 of gestation $+500 \mathrm{mg} / \mathrm{kg}$ of Vit $E$ (from day 1 gestation till day 21 postpartum).

Group VI: received 2.5 Gy of gamma rays on day 7 of gestation $+0.005 \mathrm{~mL} / \mathrm{kg}$ of Dexa (from day 1 gestation till day 21 postpartum).

Aqueous extract of Celosia argentea $L$-AECA, Gy - Gray unit ( $1 \mathrm{~Gy}=100$ rads); Vit E - Vitamin E, Dexa - Dexamethasone. The dosages used were based on published reports: AECA (Malomo et al., 2011), gamma-radiation (Malomo et al., 2005), Dexa (Malomo et al., 2006) and Vit E (Owoeye et al., 2010). The administration of 400 $\mathrm{mg} / \mathrm{kg}$ of AECA, $500 \mathrm{mg} / \mathrm{kg}$ of Vit $E$ and 0.005 $\mathrm{mL} / \mathrm{rat}$ of dexamethasone was orally given to the pregnant rats in the respective groups from gestation day 1 till birth, then the respective administrations to the mothers (breast feeding rats) continued from day one of birth till day 21 after birth. After weaning the pups on day 21, the pups in respective groups were given oral administration of AECA, Vit E and Dexa according to their body weights till day 28 postnatal day.

Each soft gelatin capsule containing $100 \mathrm{mg}$ of DL-a-tocopheryl acetate as $100 \mathrm{mg}$ vitamin $\mathrm{E}$ acetate acetate (Sinopharm Xingsha Pharmaceuticals Co. LTD, China) was obtained from Omak Pharmaceutical shop, Bodija, Ibadan, Nigeria. Each capsule was punctured with a new size $21 \mathrm{G}$ needle (Hypojet, Spain) attached to a new $1 \mathrm{~mL}$ hypothermic syringe, completely aspirated and then attached to a clean intra-gastric gavage through which each rat was administered orally the measured dose of $500 \mathrm{mg} / \mathrm{kg} /$ daily.

Dexamethasone tablets (Jiangsu Pengyao Pharmaceutical INC, China) was purchased from Omak Pharmaceutical shop, Bodija, Ibadan, Nigeria. Each $1 \mathrm{mg}$ dexamethasone tablet was dissolved in $1 \mathrm{~mL}$ of water and $0.005 \mathrm{~mL}$ of the solution was withdrawn and given per adult rat through an oral gavage.

On day 7 of gestation development the pregnant experimental animals were given Ketamine (Laborate Pharmaceutical, India) hydrochloride injection at $10 \mathrm{mg} / \mathrm{kg}$ body weight and Diazepam injection (Laborate pharmaceutical, India) at 3 $\mathrm{mg} / \mathrm{kg}$ body weight, both intraperitoneaIly. Rats were restrained by strapping them in a prone position within the well-ventilated cardboard boxes using cotton strapping. A batch of seven animals was whole body irradiated at a time with a single fraction of $2.5 \mathrm{~Gy}$ of gamma rays at a dose rate of $239.148 \mathrm{cGy} / \mathrm{min}$., for 1.19 minutes, obtained from a Cobalt- 60 source. The radiation was delivered by Bhabhatron II CO-60 machine with energy of $1.25 \mathrm{MeV}$, at source to surface distance of $80 \mathrm{~cm}$, at a depth of $3.5 \mathrm{~cm}$, and a field size of $24 \mathrm{~cm}$ by $33 \mathrm{~cm}$, with an equivalent square area of $27.79 \mathrm{~cm}^{2}$, the percentage depth dose was $88.01 \%$. There was no shielding of any part of the rat's body. The dosimetry and irradiation procedures were carried out at the Radiotherapy Department of the University College Hospital, Ibadan, Nigeria.

A subset of 35 pubs, five per each group underwent a series of behavioural tests on day 21 of postnatal life to assess motor function using the open field test to test general locomotive activity (Olopade et al., 2012). The open field is a white painted wooden box measuring $54 \mathrm{~cm}$ by $54 \mathrm{~cm}$ with black lines drawn on the floor to divide it into $18 \mathrm{~cm}$ by 18 $\mathrm{cm}$ squares. This is a square in the centre of the open field also measuring $18 \mathrm{~cm}$ by $18 \mathrm{~cm}$. The rats were observed individually in the open field for a period of 10 minutes each (Walker et al., 2012) to assess the following parameters: 
transitions or horizontal movement (measured by the number of lines crossed), rearing or vertical movement (measured by rearing, that is, number of times the rat stands on its hind leg alone) and grooming (that is sets of heterogeneous constituents comprising face washing, body licking, paw licking, head and body shaking, scratching and genital licking). All the parameters were observed and recorded manually by the same set of observers.

After obtaining blood samples from each animal, the pups of all the animals were sacrificed through cervical dislocation at different stages after their delivery for histological and histomorphometric studies on days 1, 7, 14, 21, and 28 . The whole brain was dissected and brain weights recorded. For the pubs of day 21 , the full brain was divided into two halves adopting the method of Owoeye and Ojora (2015), the right hemisphere was fixed in $10 \%$ neutral buffered formalin (10\% NBF), dehydrated using a grade ethanol series and embedded in paraffin and then sectioned at $5-6 \mu \mathrm{m}$ thickness. Sections were stained with haematoxylin and eosin and cresyl violet and then evaluated under light microscope (Olympus BX51, Tokyo, Japan) and photographed with a digital camera (100 Olympus, Olympus Optical Co. Ltd., Japan). Histomorphometery was done using microscope with a graticule attached to the eyepiece and measuring five areas of cerebellar cortex randomly and also counting the Purkinje neurons in each of the areas. The left hemisphere of the brain preserved for biochemical assays was rapidly rinsed, mopped with filter paper, weighed and kept in freshly prepared cold phosphate buffered solution (PBS) at a $\mathrm{pH}$ of 7.4 and a temperature of $4^{\circ} \mathrm{C}$ till processed.

All biochemical analyses were done on pups of day 21 only in each group. Protein concentration of brain homogenate was determined by method of Biuret reaction as described by Gornal et al., (1949) with some modifications. Lipid peroxidation (LPO) was done according to the method of Varshney and Kale (1990). Catalase (CAT) activity was determined according to the method of Sinha (1972). To assay the level of reduced glutathione (GSH), the method of Beutler et al. (1963) was followed. The level of superoxide dismutase (SOD) activity was determined by the method of Misra and Fridovich (1972). Glutathione peroxidase (GSH-Px) activity was determined according to the method of Rotruck et al. (1973).

The data were analyzed using one way Analysis of Variance (ANOVA) followed by Dunnett post hoc analysis using GraphPad Prism software version 5.04, 2010. Confidence interval was calculated at $95 \%$ and the level of significance was set at $p<0.05$.

\section{RESULTS}

Phytochemical analysis conducted on the leaves of Celosia argentea Linn indicated the presence of flavonoids, cardenolides, anthaquinones and saponin, and flavonoids and the absence of alkaloids and tannins. The body weight increases for pubs of the Irrad group was significantly $(p<0.05)$ lower when compared with the control, while the body weight increase in the Dexa + Irrad group was significantly reduced relative to the Irrad group (Figure 1). 


\section{Body weight increase}

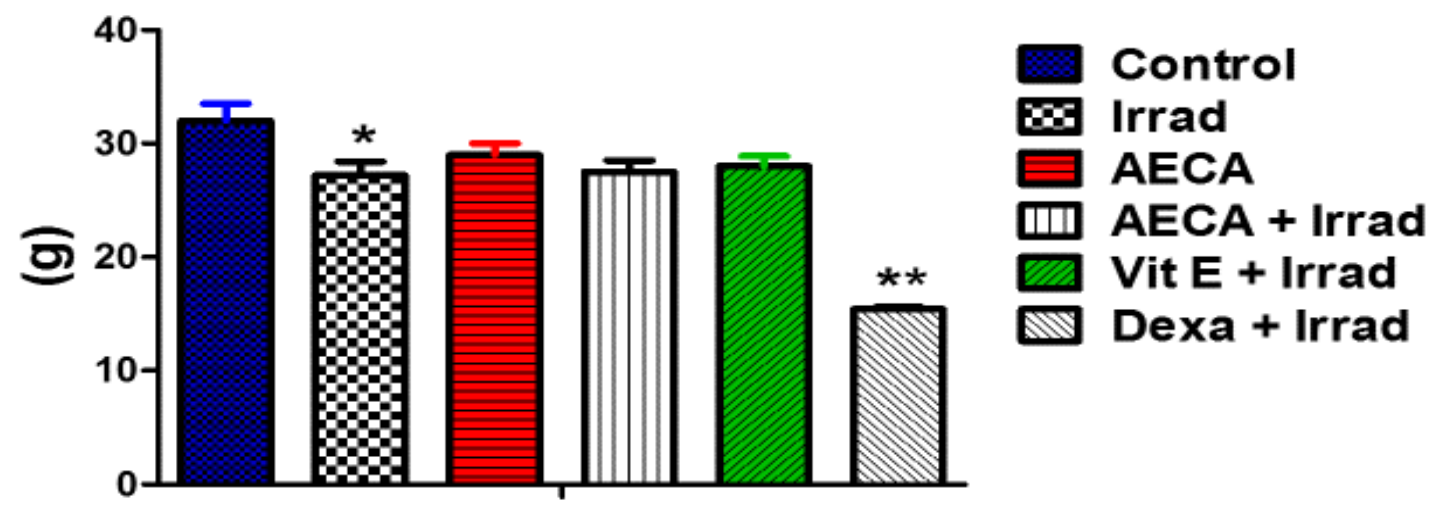

Fig. 1: Effect of treatments on body weight of rats on postpartum day 21. Values are presented as mean \pm SD of 5 animals. Irrad - Irradiation; AECA - Aqueous Extract of Celosia argentea Linn; Dexa - dexamethasone; Vit E - Vitamin E. *p $<0.05$ against Control; $* * \mathrm{p}<n \cap 5$ against Irrad.

The brain and cerebellar weights showed progressive increase in all groups from day 1 through 28 pups and there was no significant difference ( $p>0.05)$ observed within the groups as shown in Tables 1 and 2.

Table 1: Effect of treatments on brain weight

\begin{tabular}{|l|l|l|l|l|l|}
\hline Group & Day 1 & Day 7 & Day 14 & Day 21 & Day 28 \\
\hline Control & & & & & \\
\hline Irrad & $0.240 \pm 0.05$ & $0.960 \pm 0.17$ & $1.380 \pm 0.07$ & $1.400 \pm 0.08$ & $1.520 \pm 0.08$ \\
\hline AECA & $0.180 \pm 0.04$ & $1.040 \pm 0.05$ & $1.300 \pm 0.10$ & $1.380 \pm 0.04$ & $1.620 \pm 0.08$ \\
\hline AECA + Irrad & $0.240 \pm 0.05$ & $0.900 \pm 0.10$ & $1.320 \pm 0.05$ & $1.410 \pm 0.08$ & $1.620 \pm 0.08$ \\
\hline Vit E + Irrad & $0.220 \pm 0.45$ & $0.880 \pm 0.13$ & $1.260 \pm 0.29$ & $1.360 \pm 0.17$ & $1.570 \pm 0.04$ \\
\hline Dexa + Irrad & $0.206 \pm 0.01$ & $0.780 \pm 0.13$ & $1.340 \pm 0.08$ & $1.480 \pm 0.05$ & $1.600 \pm 0.16$ \\
\hline
\end{tabular}

Weight in grams. Values are presented as mean \pm SD of 5 animals. Irrad - Irradiation; AECA - Aqueous Extract of Celosia argentea Linn; Dexa - dexamethasone; Vit E - Vitamin E. 
Table 2: Effect of treatments on Cerebellar weight

\begin{tabular}{|l|l|l|l|l|l|}
\hline Group & Day 1 & Day 7 & Day 14 & Day 21 & Day 28 \\
\hline & & & & & \\
\hline Control & $0.098 \pm 0.004$ & $0.240 \pm 0.054$ & $0.294 \pm 0.009$ & $0.360 \pm 0.055$ & $0.396 \pm 0.005$ \\
\hline Irrad & $0.090 \pm 0.010$ & $0.220 \pm 0.044$ & $0.220 \pm 0.045$ & $0.338 \pm 0.057$ & $0.366 \pm 0.065$ \\
\hline AECA & $0.088 \pm 0.013$ & $0.198 \pm 0.044$ & $0.294 \pm 0.008$ & $0.336 \pm 0.059$ & $0.340 \pm 0.055$ \\
\hline AECA + Irrad & $0.092 \pm 0.008$ & $0.260 \pm 0.054$ & $0.296 \pm 0.009$ & $0.340 \pm 0.054$ & $0.320 \pm 0.044$ \\
\hline Vit E + Irrad & $0.090 \pm 0.014$ & $0.220 \pm 0.044$ & $0.260 \pm 0.055$ & $0.301 \pm 0.043$ & $0.398 \pm 0.004$ \\
\hline Dexa + Irrad & $0.094 \pm 0.008$ & $0.240 \pm 0.054$ & $0.340 \pm 0.089$ & $0.316 \pm 0.047$ & $0.360 \pm 0.055$ \\
\hline
\end{tabular}

Weight in grams. Values are presented as mean \pm SD of 5 animals. Irrad - Irradiation; AECA - Aqueous Extract of Celosia argentea Linn; Dexa - dexamethasone; Vit E - Vitamin E.

\section{Behavioural test results on day 21}

Radiation significantly $(p<0.05)$ reduced the transitions, rearings and groomings of the rats relative to the control animals, while the various

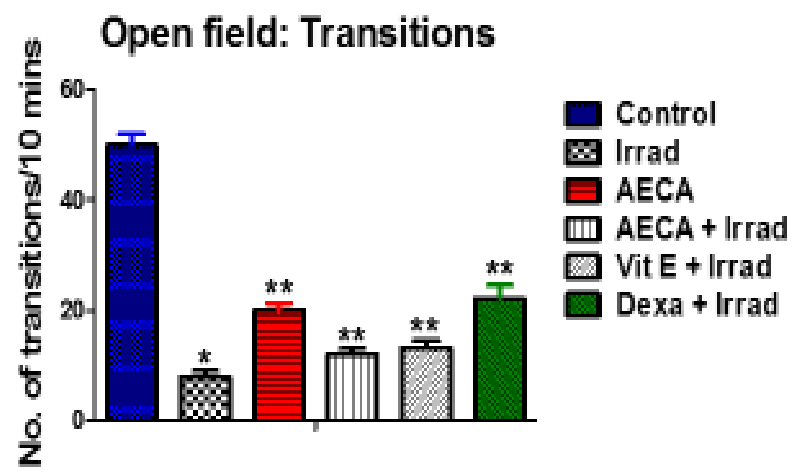

treatments ameliorated these alterations when compared with Irrad group as depicted in Figure 2.

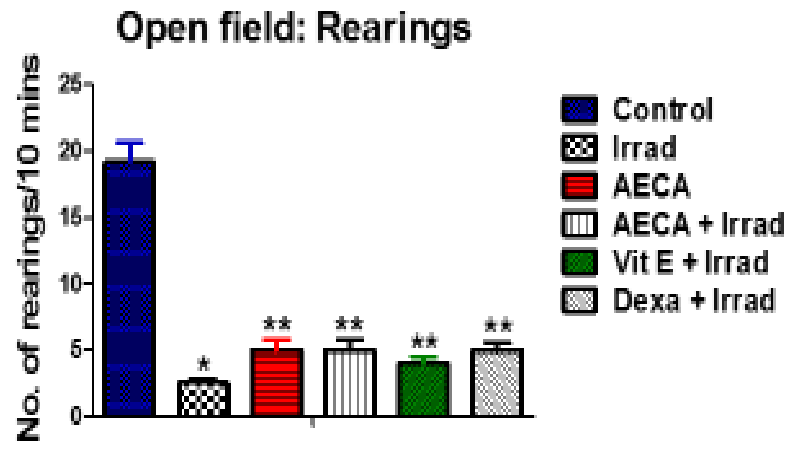

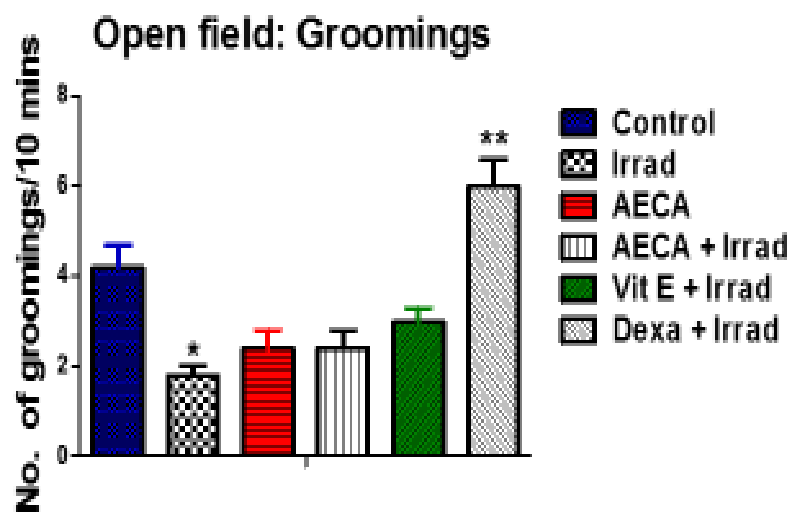

Fig. 2: Histogram of behavioural tests in all experimental groups: Open field -Transitions, Rearings and Groomings on day 21. Values are presented as mean \pm SD of 5 animals. Irrad - Irradiation; AECA - Aqueous Extract of Celosia argentea Linn; Dexa - dexamethasone; Vit E - Vitamin E. *p<0.05 against Control; **p<0.05 against Irrad. 
Table 3 presents biochemical parameters showing that radiation significantly $(p<0.05)$ increased LPO level and SOD activity but reduced GSH level when compared with the control group. However, AECA, AECA + Irrad, Vit E + Irrad and Dexa + Irrad treatments reduced LPO while increasing GSH level relative to Irrad group. The alterations in the activities of the enzyme GPx were not significant.

Figure 3 demonstrated all the treatment groups showing normal histoarchitectural layout and persistence of the external granular layer (EG) of the cerebellar cortex on the $7^{\text {th }}$ post-natal day irrespective of radiation treatment. Figures 4 and 5 demonstrated the degeneration of Purkinje neurons of the cerebellar cortex by radiation on $21^{\text {st }}$ post-natal day in H\&E as well as Cresyl violet special stain. The figures also showed the ameliorating effect of the various treatments on effect of radiation treatment.

Table 3: Effect of treatments on the radiation-induced antioxidant status of rat brain on Day 21.

\begin{tabular}{|l|l|l|l|l|l|}
\hline Groups & $\begin{array}{l}\text { GSH } \\
(\boldsymbol{\mu g} / \mathbf{m l} / \mathbf{m g})\end{array}$ & $\begin{array}{l}\text { SOD } \\
(\boldsymbol{\mu} / \mathbf{m g})\end{array}$ & $\begin{array}{l}\text { LPO } \\
(\boldsymbol{\mu M} / \mathbf{m g} \\
\mathbf{p r o t e i n})\end{array}$ & $\begin{array}{l}\text { Catalase } \\
(\boldsymbol{\mu m o l} / \mathbf{m g})\end{array}$ & $\begin{array}{l}\text { GPx } \\
(\boldsymbol{\mu} \mathbf{g} / \mathbf{m g})\end{array}$ \\
\hline Control & $1.30 \pm 0.41$ & $1.07 \pm 0.51$ & $1.07 \pm 0.12$ & $0.68 \pm 0.19$ & $58.63 \pm 6.27$ \\
\hline Irrad & $0.90 \pm 0.14^{*}$ & $1.38 \pm 0.58^{*}$ & $1.61 \pm 0.26^{* *}$ & $0.78 \pm 0.33$ & $67.62 \pm 3.25$ \\
\hline AECA & $2.20 \pm 0.41^{* *}$ & $1.47 \pm 0.19$ & $1.05 \pm 0.27^{* *}$ & $1.78 \pm 2.58^{* *}$ & $55.67 \pm 3.58$ \\
\hline AECA+Irrad & $1.90 \pm 0.29 * *$ & $1.60 \pm 0.09^{* *}$ & $1.07 \pm 0.23^{* *}$ & $1.26 \pm 1.29 * *$ & $60.82 \pm 4.24$ \\
\hline Vit E + Irrad & $1.75 \pm 0.43^{* *}$ & $1.46 \pm 0.19$ & $0.84 \pm 0.07^{* *}$ & $0.59 \pm 0.35$ & $61.36 \pm 2.62$ \\
\hline Dexa + Irrad & $2.55 \pm 0.37^{* *}$ & $1.68 \pm 0.21^{* *}$ & $0.98 \pm 0.15^{* *}$ & $0.56 \pm 0.09$ & $64.46 \pm 5.57$ \\
\hline
\end{tabular}

Values are presented as mean \pm SD of 5 animals. Irrad - Irradiation; AECA - Aqueous Extract of Celosia argentea Linn; Dexa dexamethasone; Vit E - Vitamin E. GSH- Glutathione, SOD- Superoxide dismutase, LPO- lipid peroxidation, CAT- Catalase, GSHPx-Glutathione peroxidase. * $\mathrm{p}<0.05$ against control; $* * \mathrm{p}<0.05$ against Irrad. 

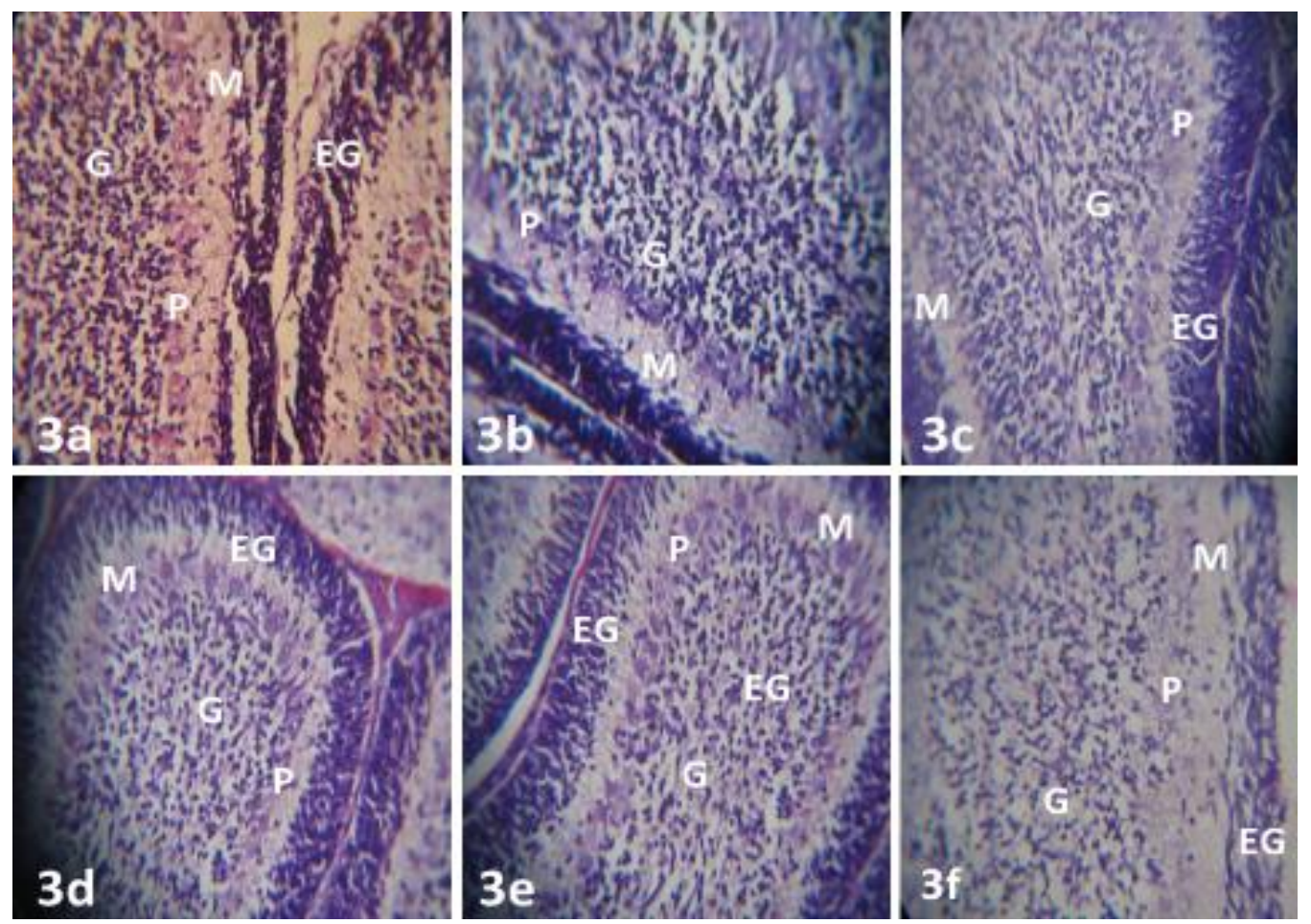

Figure 3: Representative photomicrograph of cerebellar sections on Day 7: (3a) Control (3b) Irrad (3c) AECA (3d) AECA + Irrad (3e) Vit E + Irrad (3f) Dexa + Irrad. All the treatment groups showed normal histo-architectural layout and persistence of the EG of the cerebellar cortex at this age. Irrad - Irradiation; AECA - Aqueous Extract of Celosia argentea Linn; Dexa - dexamethasone; Vit E - Vitamin E. EG, External granular layer; M, Molecular layer; P, Purkinje layer; G, Granular layer. $\mathrm{H} \& \mathrm{E} \times 280$.
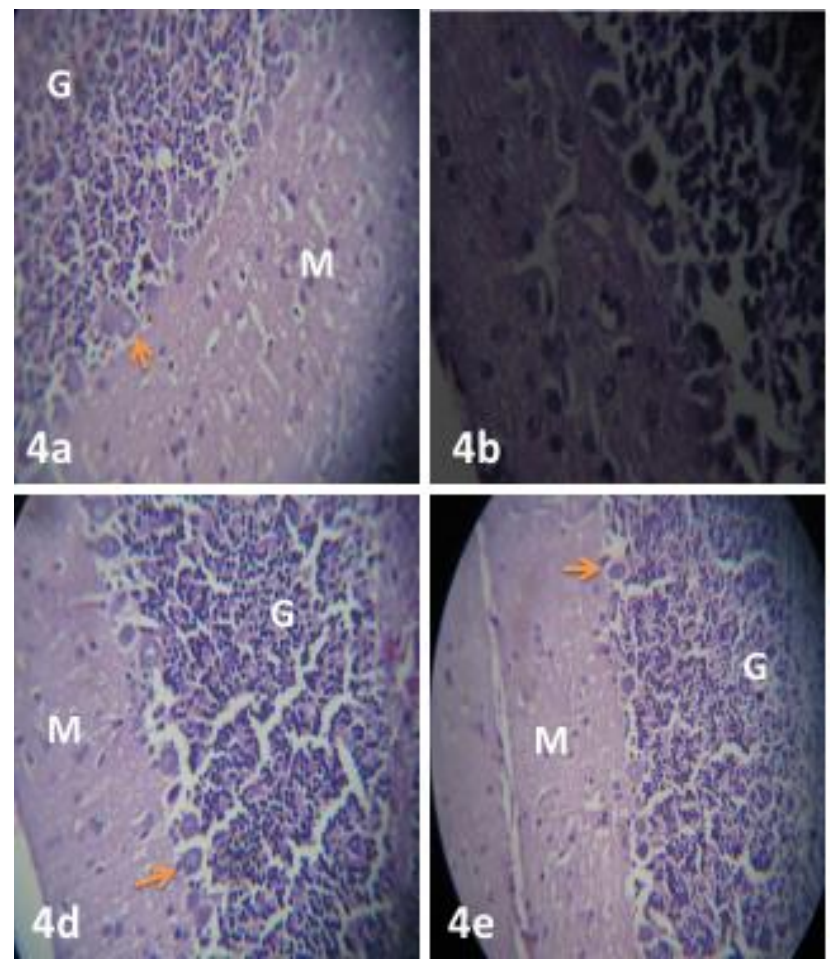
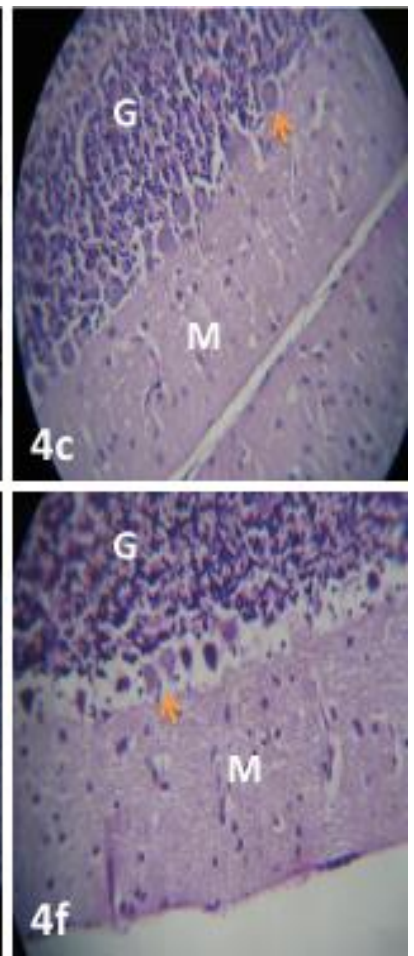

Figure 4: Representative photomicrograph of cerebellar sections on Day 21: (4a) Control showing normal histoarchitecture and preservation of cerebellar cortical components. Note the disappearance of the EG at this age (4b) Irrad group showing dark degenerated Purkinje neurons (4c) AECA group showing normal Purkinje neurons (4d) AECA + Irrad group showing normal Purkinje neurons (4e) Vit $E$ + Irrad group showing Purkinje neurons (4f) Dexa + Irrad group showing healthy and degenerated Purkinje neurons. M, Molecular layer; P, Purkinje layer; G, Granular layer. Irrad - Irradiation; AECA - Aqueous Extract of Celosia argentea Linn; Dexa dexamethasone; Vit E - Vitamin E. H\&E x 400. 

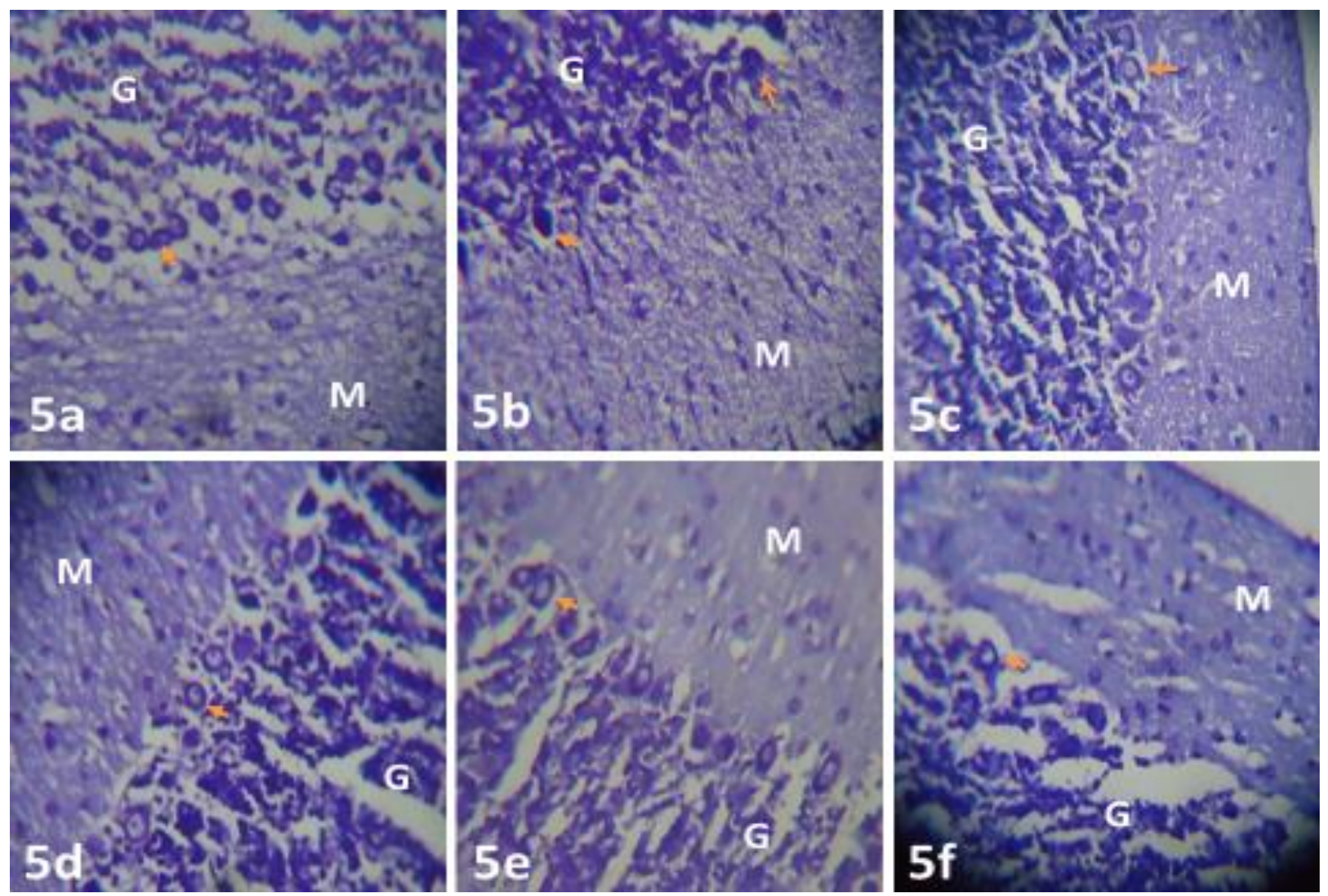

Figure 5: Representative photomicrograph of cerebellar sections on post-natal Day 21: (5a) Control, showing normal histoarchitecture and preservation of cerebellar cortical components. EG had disappeared at this age (5b) Irrad showing dark degenerated Purkinje neurons (5c) AECA showing normal Purkinje neurons (5d) AECA + Irrad showing normal Purkinje neurons (5e) Vit E + Irrad showing Purkinje neurons (5f) Dexa + Irrad showing Purkinje neurons. M, Molecular layer; Arrrow, Purkinje neuron; G, Granular layer. Irrad - Irradiation; AECA - Aqueous Extract of Celosia argentea Linn; Dexa - dexamethasone; Vit E Vitamin E. Cresyl violet stain x 400 .

Radiation significantly $(p<0.05)$ reduced the Purkinje cell layer of cerebellum when comparcu with control whereas co-treatment of radiation with $\mathrm{AECA}$, Vit $\mathrm{E}$ and Dexa increased this parameter as shown in Table 4. It can be observed that while the external granular layer (EGL) was reduced by $51.2 \%$ from day 7 to 14 of development in the control group, there was similar reduction in all other experimental groups in the order of $64.10 \%, 58.70 \%, 50.00 \%$, $52.73 \%$ and $70.00 \%$ in the Irrad, AECA, AECA + Irrad, Vit E + Irrad and Dexa + Irrad groups respectively. 
Table 4: Effect of treatments on the thickness of External granular layer on Days 7, 14 and 21 postpartum.

\begin{tabular}{|l|l|l|l|}
\hline Group & \multicolumn{3}{|c|}{ External Granular Layer $(\mu \mathrm{m})$} \\
\hline & Day 7 & Day 14 & Day 21 \\
\hline Control & $52 \pm 0.00$ & $25 \pm 0.00$ & - \\
\hline Irrad & $39 \pm 0.00^{*}$ & $14 \pm 0.00^{*}$ & - \\
\hline AECA & $46 \pm 0.01$ & $19 \pm 0.01$ & - \\
\hline AECA + Irrad & $52 \pm 0.01$ & $26 \pm 0.00^{* *}$ & - \\
\hline Vit E + Irrad & $55 \pm 0.01$ & $26 \pm 0.01^{* *}$ & - \\
\hline Dexa + Irrad & $40 \pm 0.00$ & $12 \pm 0.01$ & - \\
\hline
\end{tabular}

Values are presented as mean \pm SD of 5 animals. Irrad - Irradiation; AECA - Aqueous Extract of Celosia argentea Linn; Dexa dexamethasone; Vit E - Vitamin E. $* \mathrm{p}<0.05$ against control; $* * \mathrm{p}<0.05$ against Irrad

There was a consistency in the increase in the thickness of the ML and GL from day 7 through day 28 . The thickness of the ML increased by $237.84 \%$ from day 7 to 14 of development in the control, there was similar increment in all other experimental groups in the order of $254.17 \%$, $457.67 \%, 316.67 \%, 282.35 \%$ and $316.67 \%$ in the Irrad, AECA, AECA + Irrad, Vit E + Irrad and Dexa + Irrad groups respectively. This same pattern of increment in the thickness of PL and GL was observed. Radiation significantly $(p<0.05)$ reduced the $M L$ and $G L$ on Days 14 and 21 and PL only on Day 7 relative to control group. These values were elevated significantly $(p<0.05)$ by cotreatment of radiation with AECA and dexa as shown in Table 5 . There was a significant decrease $(p<0.05)$ in the number of Purkinje cells of the Irradiation alone group on days 14 and 21 as shown in Table 6 . However, there were in all other groups in those two days.

Table 5: Effect of treatments on the thickness of layers of cerebellar cortex Days 7, 14 and 21 postpartum.

\begin{tabular}{|c|c|c|c|c|c|c|c|c|c|}
\hline \multirow[t]{2}{*}{ Group } & \multicolumn{3}{|c|}{$\begin{array}{c}\text { Molecular Layer } \\
(\mu \mathrm{m})\end{array}$} & \multicolumn{3}{|c|}{$\begin{array}{c}\text { Purkinje layer } \\
(\mu \mathrm{m})\end{array}$} & \multicolumn{3}{|c|}{$\begin{array}{c}\text { Granular Layer } \\
(\mu \mathrm{m})\end{array}$} \\
\hline & Day 7 & Day 14 & Day 21 & Day 7 & Day 14 & Day 21 & Day 7 & Day 14 & Day 21 \\
\hline Control & $\begin{array}{l}37 \pm 0.0 \\
0\end{array}$ & $\begin{array}{l}125 \pm 0.0 \\
9\end{array}$ & $120 \pm 0.00$ & $10 \pm 0.01$ & $\begin{array}{l}30 \pm 0.0 \\
0\end{array}$ & $45 \pm 0.0$ & $\begin{array}{l}25 \pm 0.0 \\
0\end{array}$ & $149 \pm 000$ & $163 \pm 0.0$ \\
\hline Irrad & $\begin{array}{l}24 \pm 0.0 \\
0\end{array}$ & $\begin{array}{l}85 \pm 0.01 \\
*\end{array}$ & $89 \pm 0.00^{*}$ & $3.6 \pm 0.01 *$ & $\begin{array}{l}28 \pm 0.0 \\
0\end{array}$ & $30 \pm 0.0$ & $\begin{array}{l}14 \pm 0.0 \\
0\end{array}$ & $\begin{array}{l}115 \pm 0.01 \\
*\end{array}$ & $121 \pm 0.00 *$ \\
\hline AECA & $\begin{array}{l}26 \pm 0.0 \\
0\end{array}$ & $\begin{array}{l}145 \pm 0.0 \\
2 * *\end{array}$ & $\begin{array}{l}150 \pm 0.00 * \\
*\end{array}$ & $7 \pm 0.00$ & $\begin{array}{l}30 \pm 0.0 \\
0\end{array}$ & $44 \pm 0.0$ & $\begin{array}{l}19 \pm 0.0 \\
1\end{array}$ & $\begin{array}{l}149 \pm 0.15 \\
* *\end{array}$ & $\begin{array}{l}153 \pm 0.02 * \\
*\end{array}$ \\
\hline $\begin{array}{l}\text { AECA + } \\
\text { Irrad }\end{array}$ & $\begin{array}{l}30 \pm 0.0 \\
1\end{array}$ & $\begin{array}{l}125 \pm 0.0 \\
1 * *\end{array}$ & $\begin{array}{l}151 \pm 0.00 * \\
*\end{array}$ & $\begin{array}{l}10 \pm 0.00 * \\
*\end{array}$ & $\begin{array}{l}33 \pm 0.0 \\
0\end{array}$ & $44 \pm 0.0$ & $\begin{array}{l}26 \pm 0.0 \\
0\end{array}$ & $\begin{array}{l}150 \pm 0.00 \\
* *\end{array}$ & 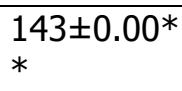 \\
\hline $\begin{array}{l}\text { Vit E + } \\
\text { Irrad }\end{array}$ & $\begin{array}{l}34 \pm 0.0 \\
1\end{array}$ & $\begin{array}{l}130 \pm 0.0 \\
1 * *\end{array}$ & $\begin{array}{l}153 \pm 0.00 * \\
*\end{array}$ & $12 \pm 0.0 * *$ & $\begin{array}{l}31 \pm 0.0 \\
0\end{array}$ & $44 \pm 0.0$ & $\begin{array}{l}22 \pm 0.0 \\
1\end{array}$ & $\begin{array}{l}140 \pm 0.01 \\
* *\end{array}$ & $\begin{array}{l}\text { 165士0.00* } \\
*\end{array}$ \\
\hline $\begin{array}{l}\text { Dexa + } \\
\text { Irrad }\end{array}$ & $\begin{array}{l}30 \pm 0.0 \\
1\end{array}$ & $\begin{array}{l}125 \pm 0.0 \\
1 * *\end{array}$ & $\begin{array}{l}121 \pm 0.00 * \\
*\end{array}$ & $7 \pm 0.00$ & $\begin{array}{l}29 \pm 0.0 \\
0\end{array}$ & $30 \pm 0.0$ & $\begin{array}{l}12 \pm 0.0 \\
0\end{array}$ & $\begin{array}{l}155 \pm 0.01 \\
* *\end{array}$ & $\begin{array}{l}153 \pm 0.00 * \\
*\end{array}$ \\
\hline
\end{tabular}

Values are presented as mean \pm SD of 5 animals. Irrad-Irradiation; AECA-Aqueous Extract of Celosia argentea Linn; Dexa-dexamethasone; Vit E-Vitamin E. * $\mathrm{p}<0.05$ against control; $* * \mathrm{p}<0.05$ against Irrad. 


\section{Density of Purkinje cells:}

Table 6: Mean density of Purkinje cells in post-natal days (per $\mathrm{mm}$ ).

\begin{tabular}{|l|l|l|l|}
\hline Groups & Day 14 & Day 21 & Day 28 \\
\hline Control & $23.75 \pm 4.78$ & $20.75 \pm 0.95$ & $22.75 \pm 4.85$ \\
\hline Irrad & $15.00 \pm 5.77^{*}$ & $15.25 \pm 6.07 *$ & $20.25 \pm 0.50$ \\
\hline AECA & $29.50 \pm 0.57^{* *}$ & $25.00 \pm 5.77^{* *}$ & $22.75 \pm 4.86$ \\
\hline AECA + Irrad & $22.75 \pm 4.85^{* *}$ & $25.25 \pm 5.50^{* *}$ & $20.25 \pm 0.50$ \\
\hline Vit E + Irrad & $22.75 \pm 4.85^{* *}$ & $25.50 \pm 5.26 * *$ & $20.25 \pm 0.50$ \\
\hline Dexa +Irrad & $20.00 \pm 0.82^{* *}$ & $25.50 \pm 5.80^{* *}$ & $25.00 \pm 5.77 * *$ \\
\hline
\end{tabular}

Values are presented as mean \pm SD of 5 animals. Irrad - Irradiation; AECA - Aqueous Extract of Celosia argentea Linn; Dexa - dexamethasone; Vit E - Vitamin E. * $\mathrm{p}<0.05$ against control; **p $<0.05$ against Irrad.

\section{DISCUSSION}

The overall outcome of our results demonstrated that radiation toxicity caused gross morphometric, biochemical, histological and histomorphometric alterations in the neonatal rat cerebellum investigated. Changes in organ weight induced by toxicants or substances have been shown to be a reliable marker of toxicity (Elias \& Nelson, 2012). In this experiment, radiation has proven to be toxic to the brain as shown by the body and cerebella weight reduction. The reduction in body weight of the animals of the Irrad group is in agreement with the report of De Santis et al. (2007) that prenatal exposure to ionizing radiation can interfere with embryonic and fetal development thus causing increased incidence of malformation and intrauterine growth restriction. Similarly, the reduction in the body weight of rats in the Dexa + Irrad group may be due to the fact that dexamethasone readily crosses the placenta and can cause intrauterine growth retardation and affects brain growth and development in pregnant animals (Monson and Schoenstadt, 2013).

Furthermore, our results showed a reduction in both transitional and rearing frequencies in all groups that were irradiated suggesting an impairment of motor activity in the cerebral cortical, subcortical or/and cerebellar portions of the brain which are movement-control related. Since irradiation was global, it seems that the ameliorating effect of AECA, vitamin $E$ and dexamethasone were unable to reverse these. However, co-treatment of radiation with AECA, vitamin $\mathrm{E}$ and dexamethasone were able to mitigate the effect of radiation on frequency of grooming and forearm grip strength. Earlier reports demonstrated that irradiation has dosedependent influence on the brain centers involved in control of innate behavioural function connected with response to environment in rats (Kiskova et al., 2008). It might be that the nonuniform response of these parameters to the interventions is due to the $2.5 \mathrm{~Gy}$ dose of radiation used in this experiment.

The significant reduction in GSH and an increase in MDA level, an end product of LPO in the Irrad alone group suggested that a state of oxidative stress occurred in the brains of the rats which might be due to increase in peroxidation of unsaturated fatty acids in the brain as a result of irradiation injury, a finding consistent with the reports of Adaramoye et al., (2010) and Owoeye et al. (2010). MDA is the most often used biomarker to investigate oxidative damage in lipids due to cellular injury or disease (Uttara et al., 2009). In this study, AECA alone or as AECA + Irrad treatment decreased LPO activities, an 
indication that AECA was able to mitigate the oxidative stress generated by radiation treatment. Such was also the case of the Vit E + Irrad and Dexa + Irrad treatments which also ameliorated the free radical generated. Owoeye et al. (2011) reported that radiation toxicity was mediated by the mechanism of free radical injury of tissues thereby causing oxidative damage. The central nervous system is particularly susceptible to oxidative stress, mainly because it is rich in polyunsaturated fatty acids, accumulate redox metal ions, consumes large amount of oxygen, is relatively low in antioxidants and is composed largely of non-mitotic highly differentiated cells that are difficult to repair when damaged (Singhal et al., 2013).

While radiation increased the activities of brain SOD, CAT and GSH-Px, there were further increased activities in AECA and the cotreatment groups which indicated an adaptive response of these enzymes to mitigate the effect of further free radical generation. The activities of SOD and CAT were also observed to be higher in AECA + Irrad group than in Vit E + Irrad and Dexa + Irrad groups. Singhal et al. (2013) reported that SOD works in synergy with CAT and CAT is mechanistically more effective than GSH-Px in neurons and may be alternate source for oxygen, perhaps assisting with neuroprotection in hypoxic conduction. The $A E C A$, Vit $E$ and Dexa to some extent might possibly have a role in improving the synthesis of the antioxidant enzymes which in turn protected the cells from reacting oxygen species (ROS) thus complementing antioxidant defense mechanism of the animals. The significant increase in GSH levels of AECA and AECA + Irrad groups when compared with control and other irradiated groups demonstrated antioxidant effect probably because of its phenolic compounds (Malomo et al., 2011). Researchers have shown that GSH being a substrate or cofactor for a number of protective enzymes (GSHperoxidase, GPH s-transferase, or Glatoxalase) is reduced during oxidative stress (Halliwell and Gutteridge, 2007; Uttara et al., 2009). It is conceivable therefore, that the increase in GSH observed in this study, might possibly be due to enzyme induction (Vilic et al., 2010).

Radiation-induced free radicals generation can lead to cell death by modes of necrosis and apoptosis (Gilgun-sherki et al., 2002) while irradiation causes damage to living tissues as reported by other researchers (De Santis et al., 2007; Owoeye et al., 2011). Along this line, Arturo (2010) reported that low doses of irradiation have multiple effects on development of the cerebellum namely: significant reduction of the number of granule and basket cell, Purkinje cells are misaligned and have abnormal dendrites and reduction in the overall size of the cerebellum. These observations are consistent with this study as observed in reduction of granular layer of Irrad group on day 7, reduction in external granular and granular layers on day 14 , significant reduction in Purkinje and granular layers on day 21 and molecular and Purkinje layers on day 28 and histologically demonstrated in the necrotic Purkinje cells in the photomicrograph of day 21 of Figures 5 and 6.

The observed reduction (Table 4) in the thickness of external granular layer (EGL) of the cerebellum in the Dexa + Irrad group from 40 $\mu \mathrm{m}$ on postnatal day 7 to $12 \mu \mathrm{m}$ on postnatal day 14 (a 70\% decrease) could be due to endogenous glucocorticoid stimulation which during normal development is thought to selectively signal the elimination of the EGL once the production of new neurons is complete and radiation therapy may disrupt cerebellar development through the rapid induction of apoptosis in the cerebellar external granular layer (Noguchi, 2014). The cerebellar EGL is a transient proliferative region responsible for the production of $90 \%$ of neurons in the cerebellum (Herculano-Houzel, 2009). After the complete elimination of the EGL on postnatal day 21 in rats (Altman and Bayer, 1978), the molecular layer (ML) then becomes the outermost layer of the cerebellar cortex as demonstrated in Figure 5 of images showing the cerebellar cortex on postnatal day 28. The reduction of the thickness of $\mathrm{ML}, \mathrm{PL}, \mathrm{GL}$ of the cerebellar cortex, and the 
density of the Purkinje neurons by radiation shown in Tables 5 and 6, might be due to toxicity of radiation causing neuronal death in those layers in agreement with published reports (Gilgun-Sherki et al., 2002). The consequences of this damage would be a reduction in the effectiveness of the Purkinje cells which are the focal neurons of the cerebellum, affecting movement, posture, coordination and other cerebellum-dependent cognitive function (Afifi and Bergman, 2005).

The amelioration of the various gross morphometric, biochemical, histological and histomorphometric alterations in the experimental neonatal rats by the antioxidant activities of AECA and Vit $E$, and antiinflammatory property of Dexa mitigated the toxicity induced by radiation treatment thus avoiding the consequences that might have arisen. The partial neuroprotection offered the developing cerebellum by dexamethasone is in agreement with the earlier findings of Malomo et al. (2006). In particular, these findings have confirmed reports by other researchers that Celosia Argentea Linn has chemical components and biological activities that could mitigate oxidative stress being one the mechanism of radiation toxicity (Malomo et al., 2011; Gbadamosi et al., 2012).

In conclusion, this study demonstrated that 2.5 Gy gamma-radiation administered on pregnant rats on day 7 of foetal development, caused damage to rat's foetuses in-utero which manifested in post-natal life. Also, the antioxidant properties of the aqueous extract of Celosia argentea Linn was able to mitigate the effect of the damage caused to the developing rat brain in-utero and was found to be better than Vitamin $\mathrm{E}$ and Dexamethasone in some parameters. Although these findings added to existing literature that antioxidants found in fresh leafy vegetables like Celosia argentea Linn can be used to protect against irradiation injury, further studies using histochemical techniques are warranted to yield more understanding of these observations.

ACKNOWLEDGEMENTS: Authors gratefully acknowledge Dr. (Mrs.) T. N. Elumelu, Mrs. A. O. Ekisola and all the staff of Radiotherapy Department, $\mathrm{UCH}$, Ibadan, for technical assistance during the irradiation procedures at the Department of Radiotherapy, University College Hospital, Ibadan, Nigeria. We appreciate the kindness of Prof. E. O. Farombi, who permitted the conduction of biochemical assays in his Drug Metabolism \& Toxicology Research Laboratories, Department of Biochemistry, College of Medicine, University of Ibadan, Nigeria.

DECLARATION OF INTEREST: The authors declare that there is no conflict of interest in this study. The authors alone are responsible for funding of this research and the content and writing of this paper.

\section{REFERENCES}

1. Adaramoye OA. 2010. Protective Effect of Kolaviron, Biflavonoid from Garcinia kola Seeds, in Brain of Wistar Albino Rats Exposed to Gamma-Radiation. Biol Pharm Bull 33(2): 260-266.

2. Afifi AK, Bergman RA. 2005. Functional neuroanatomy: Text and Atlas, 2nd edition, McGraw- Hill, New York p. 201-222.

3. Altman J, Bayer SA. 1978. Time and distribution of a new cell type in the rat cerebellar cortex. J Comp Neurol 179: 23-48.

4. Arturo A. (2010). Irradiation damage increases Purkinje neuron heterokaryons in neonatal cerebellum. Ann Neural 66(1): 100-109.

5. Beutler E, Duron, O, Kelly B.M. 1963. Improved method for the determination of blood glutathione. J Lab Clin Med 61: 882-8.

6. Bharrhan S, Chopra K, Rishi IP. 2010. Vitamin E Supplementation Modulates Endotoxin-induced Liver Damage in a Rat Model. Am J Biomed Sci 2(1): 51-62. 
7. Borek C. 2004. Antioxidants and Radiation Therapy. J Nutr 134(11): 3207-3209.

8. De Santis M, Cesari E, Nolili E, Straface G, Cavaliere AF, Caruso A. 2007. Radiation Effect on the Developing Fetus, Birth Defects. Res C Embryo Today 81(3): 177-82.

9. Elias A, Nelson B. 2012. Toxicological effect of ciprofloxacin on testicular function of male Guinea pigs. Asian J Bio Sci 3(2): 384-390.

10. Gbadamosi IT, Alia AE, Okolosi O. 2012. In-vitro Antimicrobial Activities and Nutritional Assessment of Roots of Ten Nigerian Vegetables. N Y Sci J 5(12): 234-240.

11. Gilgun-Sherki Y, Rosenbaum Z, Melamed E, Offen D. 2002. Antioxidant therapy in acute Central Nervous System Injury: Current state. Pharmacol Rev 4(2): 271-84.

12. Gornal AG, Bardawell CJ, David MM. 1949. Determination of serum proteins by means of the Biuret reaction. J Biol Chem 177: 751-766.

13. Grubben GJH, Denton OA. 2004. Plant resource of Tropical Africa 2, Vegetables. Prota Foundation/ Baukhuys Publishers CTA. Wageningen, Netherlands. p 167-173.

14. Halliwell B, Gutteridge JMC. 2007. Free radicals in Biology and Medicine: Cellular responses to oxidative stress, adaptation, damage, repair, senescence, and death. $4^{\text {th }}$ edition. Oxford University Press p. 187-267.

15. Herculano-Houzel S. 2009. The human brain in numbers: a linearly scaled up primate brain. Front Hum Neurosci (3)31: 1-11. https://doi.org/10.3389/neuro.09.031.2009.

16. Owoeye O, Ojora KA. 2015. Tomato pomace alleviated motor abnormality, oxidative impairments and neurotoxicity induced by Lead acetate in male rats. Afr J Biomed Res 18(3): 201-201.

17. Kiskova J, Smajda B. 2008. Open field behaviour and habituation in rat irradiated in the head with gamma ray. ACTA Physiol Hung 95(3): 307-12.

18. Malomo AO, Owoeye O, Elumelu TN, Akang EEU, Adenipekun A, Campbell OB, Shokunbi MT. 2005. The effect of dexamethasone, metronidazole and ascorbic acid on the morphological changes induced by gamma rays on the spinal cord of Wistar rats. Afr J Med Med Sci 34(2): 161-165.

19. Owoeye O, Elumelu TN. 2015. Tomato consumption protected against gamma radiation-induced behavioural and histological alterations in the hippocampus and cerebellum of rats. Nig Vet J 36(3): 1240-1250.

20. Malomo AO, Ekpo OE, Imosemi IO, Owoeye O, Osuagwu FC, Avwioro OG, Shokunbi MT. 2006. Neuroprotective Effect of Dexamethasone on the Morphology of the irradiated Post Natal Developing Cerebellum of Wistar Rat (Rattus norvegicus). Int J Morphol 24(2): 221-229.

21. Malomo SO, Ore A, Yakubu MT. 2011. Invitro and invivo antioxidant activities of the aqueous extract of Celosia argentea var cristata leaves: Indian J Pharmacol 43(3): 278-285.

22. Misra HP, Fridovich I. 1972. The role of superoxide anion in the auto-oxidation of epinephrine and a simple assay for superoxide dismutase. J Biol Chem 247: 3170-75.

23. Monson K, Schoenstadt A. 2013. Dexamethasone: www.arthritis.emedtv.com/m/dexamethsone. Accessed 19th December 2013.

24. Noguchi K K. 2014. Glucocorticoid induced cerebellar toxicity in the developing neonate: implication for glucocorticoid therapy during bronchopulmonary dysplasia. Cells 3: 36-52; www.mdpi.com/journal/cells. doi:10.3390/cells3010036

25. Ogbru O. 2012. Dexamethasone oral, Decadron, Dexpak. www.medicinenet.com. Accessed 19th Dec. 2013.

26. Olopade FE, Shokunbi MT, Siren A. 2012. The relationship between ventricular dilatation, neuropathathological and neurobehavioural changes in hydrocephalic rats. Fluids Barriers CNS 9: 19.

27. Owoeye O, Adesida A, Onwuka SK, Farombi EO. 2010. Gamma radiation effects on the brain of rats: antioxidant and radioprotective properties of Vernonia amygdalina leaf extract. Int J Biol Chem Sci 4(6): 2324-2336. 
28. Owoeye O, Farombi EO, Onwuka SK. 2011. Gross Morphometric Reduction of rats' cerebellum by gamma irradiation was mitigated by pretreatment with Vernonia amygdalina leaf extract: Rom J Morphol Embryol 52(1): 81-88.

29. Owoeye O, Malomo AO. 2015. Launaea taraxacifolia leaf extract protected against gamma radiation-induced haematological, behavioural and histological alterations in the hippocampus and cerebellum of rats. Arch Basic and App Med 3: 21-28.

30. Public Health Service (PHS). 1996. Public Health Service Policy on Humane Care and User of Laboratory Animals. US Department of Health and Human Services. Washington, DC 99-158.

31. Rotruck JT, Pope AL, Ganther HE, Swanson AB, Hafeman DG, Hoekstra WG. 1973. Selenium: biochemical role as a component of glutathione peroxidase. Science 179: 588-590.

32. Sarkar R, Mukherjee A, Biswas R, Biswas J, Roy M. 2014. Sulphoraphane, by virtue of its antioxidant potential down-regulates HSP90 in leukemia cells. Int J Curr Microbiol App Sci 3(1): 476-486.

33. Sezen O, Ertekin MV, Demircan B, Karshlioglu I, Erdogan F, Kocer I, Calik I, Gepdiremen A. 2008. Vitamin $\mathrm{E}$ and L-carnitine, separately or in combination, in prevention of radiation induced brain and retinal damages. Neurosurg Rev 31(2): 205-213.

34. Singhal A, Morris VB, Labhasetwar V, Ghorpade A. 2013. Nanoparticle-mediated catalase delivery protects human neurons from oxidative stress. Cell Death and Disease (2013) 4, e903; doi:10.1038/cddis.2013.362.

35. Sinha, A.K. 1972. Colorimetric Assay of Catalase. Analytic Biochem 47: 389-394. http://dx.doi.org/10.1016/0003-2697(72)90132-7

36. Uttara B, Singh AV, Zamboni P, Mahajan RT. 2009. Oxidative stress and Neurodegenerative diseases: a review of upstream and downstream antioxidant therapeutic options. Curr Neuro Pharma Col 7(1): 65-74.

37. Varshney R, Kale RK. 1990. Effects of calmodulin antagonists on radiation-induced lipid peroxidation in microsomes. Int J Radiat Biol 58 (5): 733-43.

38. Verma H, Demla M. 2012. Standardization of Whole Plant of Celosia argentea Linn. Int J Pharm Sci Res 3(8): 2695-2699.

39. Vilic M, Alandrovic J, Ljubic BB, Miljanic S, Kraljevic P. 2010. Effect of low dose gamma- radiation upon anti-oxidant enzyme in chick embryo liver. Arch Geflugek 74(4): 274 -278.

40. Walker TL, Vukovic J, Koudijs MM, Blackmore DG, Mackay EW, Skykes AM, Overall RW, Hamilin AS, Bartlett FP. 2012. Prolactin stimulates precursor cells in the adult mouse hippocampus PlosOne 7(9): e44371. doi:10.1371/journal.pone.0044371 